\title{
How to Approach Real Mathematical Modeling in Surge Capacity: Clinical Review
}

\author{
Ali Ziaee ${ }^{* \#}$, Shervin Assariं2, Helia Ghanean ${ }^{3}$, A. Jalali ${ }^{4}$, Saleem Abboud Youssef ${ }^{5}$ \\ ${ }^{1}$ Emergency Department, Saudi German Hospital, Dubai, UAE \\ ${ }^{2}$ University of Michigan, Michigan, USA \\ ${ }^{3}$ Research Associate, UHN, Toronto, Canada \\ ${ }^{4}$ Karolinska Institute, Sweden \\ ${ }^{5}$ Emergency Specialist, Saudi German Hospital, Dubai, UAE \\ Email: "Sali_ziaee@yahoo.com
}

How to cite this paper: Ziaee, A., Assari, S., Ghanean, H., Jalali, A. and Youssef, S.A. (2017) How to Approach Real Mathematical Modeling in Surge Capacity: Clinical Review. Open Journal of Emergency Medicine, 5, 85-91.

https://doi.org/10.4236/ojem.2017.52008

Received: May 12, 2017

Accepted: June 23, 2017

Published: June 26, 2017

Copyright ( 2017 by authors and Scientific Research Publishing Inc. This work is licensed under the Creative Commons Attribution International License (CC BY 4.0).

http://creativecommons.org/licenses/by/4.0/

\section{(c) (i) Open Access}

\begin{abstract}
Objectives: Science of surge is one of most important topics in the realm of disaster preparedness. Since 2006, after Academic Emergency Medicine (AEM) Consensus Conference, few articles with quantitative data address decision making in surge capacity. The aim of this article is looking forward to the facts about mathematical modeling and proposes real modeling in decision making to have better outcome. Methods: Literature Research was performed on database for the last ten years (2007-2017). Articles with mathematical modeling were separated and classified based on the usage of them in the field. Results: All current mathematical studies compared based on prehospital and hospital setting and flexibility in change of global level of care in time. Integrated model of sigmoid curve and HASC (Hospital Acute Care Surge Capacity) with name B-H integrated modeling in two-hour interval proposed. Conclusion: This study shows dynamic process of disaster planning based on outcome and reality. The proposed model makes surge capacity more predictable and adjustable.
\end{abstract}

\section{Keywords}

Surge, Capacity, Disaster, Mathematical, and Modeling

\section{Introduction}

Nowadays, one of the most import focuses of discussion in the realm of disaster preparedness is surge capacity.

Hospital point of view, surge capacity is the fundamental core of medical response and it is part of medical resources of the community [1] [2] [3] [4].

${ }^{\star}$ Ali Ziaee, MD, European Master of Emergency Medicine. 
In 2006, Academic Emergency Medicine (AEM) published an important topic on the "Science of Surge" [5], summarizing the proceedings of the AEM consensus conference on the same subject [6].

Almost after ten years from this consensus conference, No identified articles concentrated specifically on determining key decision-makers [6] [7]; rather, the articles we detected to assess decision response efficacy in general procedures in terms of hospital and pre-hospital setting.

In the review of 10 years research including this study (2007 to 2017), there have been some valuable improvements in the concepts of measuring surge and creating surge capacity. However, among articles referred as being concerned with surge, few quantitative articles address the predefined results [6]. As the first objective the review in this article describes the quantitative researches in literature with regard to decision making in command-control section and surge capacity in disaster. Second objective is looking forward the usage of each mathematical modeling in terms of control of surge capacity, distribution of patients between centers and propose new modeling for command-control section to have better outcome based on the current findings.

\section{Methods}

Quality appraisal of article review selected as checklist of study. In first step, extensive research conducted for the last ten years (2007-2017). The search criteria included PubMed, Embase, MEDLINE, and Cochrane library Database. Clinical key as a software used to classify systemic reviews, journals, books and reviews precisely. Search Criteria terms included individually and in combination: "disaster", "surge", "capacity", "mathematical" and "modeling”.

English language full-text articles were included. Abstracts are classified into two groups: relevant and non relevant. The accepted articles made the source of our research. Only full articles in English journals were included. Letters, books to the editor were excluded. Non-quantitative articles were considered separately and did not include in study.

Articles with mathematical modeling were separated and classified based on the usage of them in the field. Validity of each mathematical study confirmed by the methodology of study.

\section{Results}

A total of 83 unique articles were found using quantitative surge capacity in disaster. (Figure 1) Among relevant abstract and articles, total of 31 addressing analysis focus on decision making those 5 articles among them made a mathematical modeling. Systematic review of Consensus conference was so helpful, although some articles did not find in that review.

Table 1 shows conclusion of each study in surge capacity. The main concept of each study explained based on author opinion.

After detailed review of each framework of mathematical modeling, this idea raised how previous authors used each modeling in each scenario. One of the 
Table 1. Quantitative Studies of Surge Capacity with Mathematical Modelings.

\begin{tabular}{|c|c|}
\hline Articles & Conclusion: \\
\hline Bayram, et al. [1] 2011 & $\begin{array}{l}\text { Hospital bed surge capacity mathematically benchmarked to be } \\
18 \% \text { of the staffed hospital bed capacity. This is defined as ratio } \\
\text { of Emergency beds to emergency time to each critical patient. }\end{array}$ \\
\hline Hirshberg, et al. [7] 2005 & $\begin{array}{c}\text { Surge capacity is defined in sigmoid shaped curve } \\
\text { based on global level of care. }\end{array}$ \\
\hline Rivera, et al. [10] 2006 & $\begin{array}{l}\text { The capacity measured in two type of trauma centers. } \\
\text { ED throughput in } 6 \text { hours in level I trauma centers } \\
\text { (median } 39 \text { ED beds) was } 117 \text { patients and } 75 \text { patients in } \\
\text { level II centers (median } 25 \text { ED beds). }\end{array}$ \\
\hline De Boer, et al. [11] 1999 & $\begin{array}{l}\text { Mathematical method of each hospital could care for } \\
\text { a number of critically and moderately injured patients } \\
\text { equivalent to } 0.5 \text { to } 1 \text { patient per } 100 \text { hospital beds per hour. }\end{array}$ \\
\hline Halpen, et al. [8] 2003 & $\begin{array}{l}\text { So many items were evaluated such the use of personal protective } \\
\text { equipment, needs assessment, the mobilization of human and } \\
\text { material resources, the organization and performance of triage, } \\
\text { the management of explosion-specific injuries, } \\
\text { the organization of patient flow through the ED, } \\
\text { and the efficient determination of patient disposition. }\end{array}$ \\
\hline Hick, et al. [9] 2004 & $\begin{array}{l}\text { From facility level to higher part, surge capacity should be } \\
\text { considered and activated in multiple levels .Plans for "surge capacity" } \\
\text { must thus be made to accommodate a large number of patients. }\end{array}$ \\
\hline
\end{tabular}

$\mathrm{ED}=$ Emergency Department.

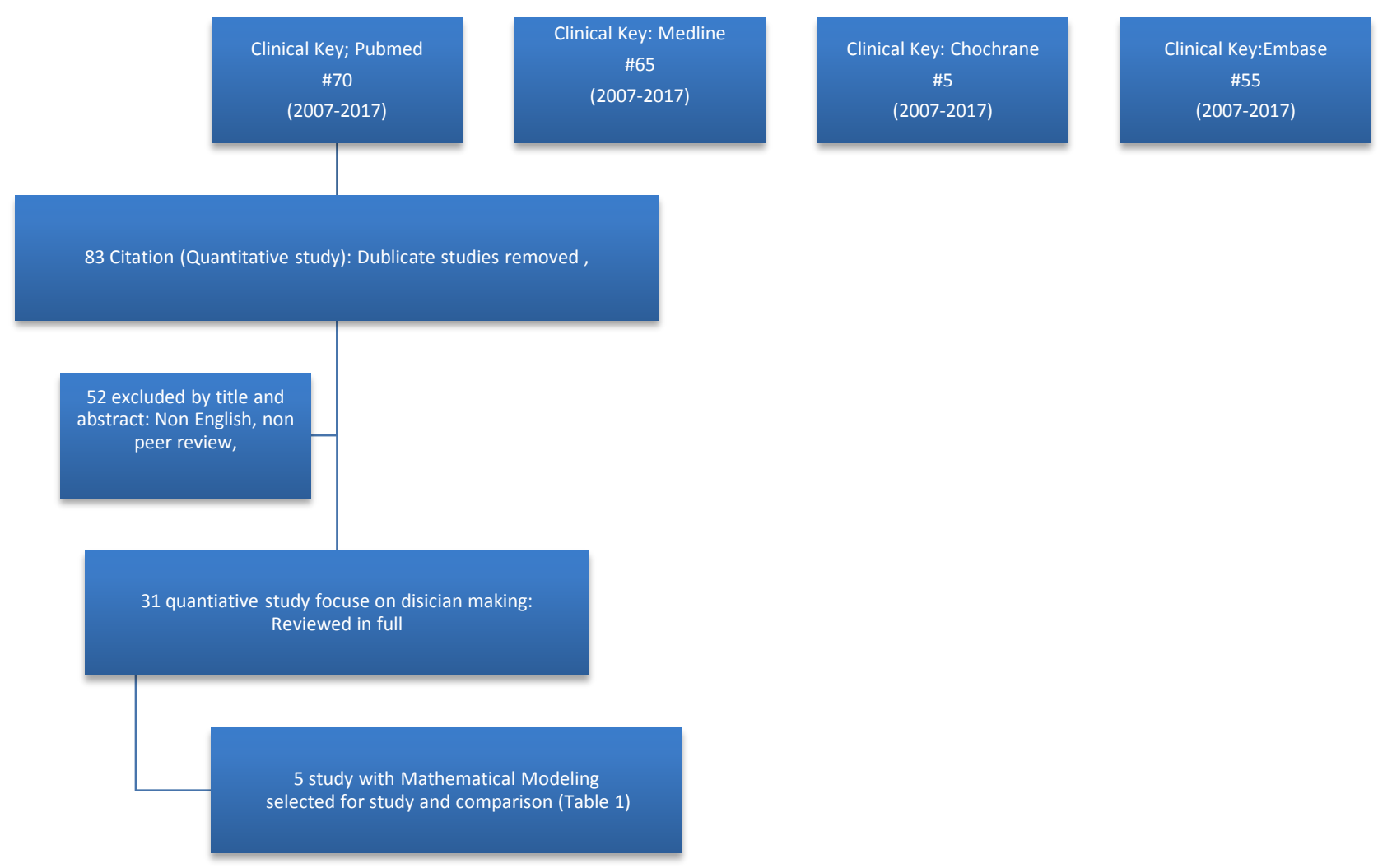

Figure 1. Flow diagram for mathematical modeling in surge capacity selection process. 
most important modeling was Hirshberg et al. [7] study, which was based on quality of care in surge capacity. Bayram et al. [1] mentioned that their study looked at quality of care of Hirshberg et al. [7] as well. These two main studies worked well on hospital bed surge capacity, although there were some mathematical modeling, which explained by Halpen et al. [8] and Hick et al. [9]. Final report of Hirshberg et al. [7] predicts sigmoid-shaped relationship between level of care and casualty load, with upper flat portion of the curve related to the surge capacity.

Table 2 is the summary of prediction of each model in surge capacity. The mainstay part of this summary is usage of each model in decision-making in command control of incident in terms of hospital setting or pre hospital setting. Flexibility of each study compared and defined as considering change of level of care in Time. Studies got marks for general modeling if they were not based on simulation or single scenario.

\section{Discussion}

It is true any mathematical modeling is not able to depict reality, because of that approaching to any model should be done with caution.

This review reached to this point that each hospital needs to have its own global level of care in non-linear regression curve. Therefore it is advised to es-

Table 2. European Master of Disaster Medicine.

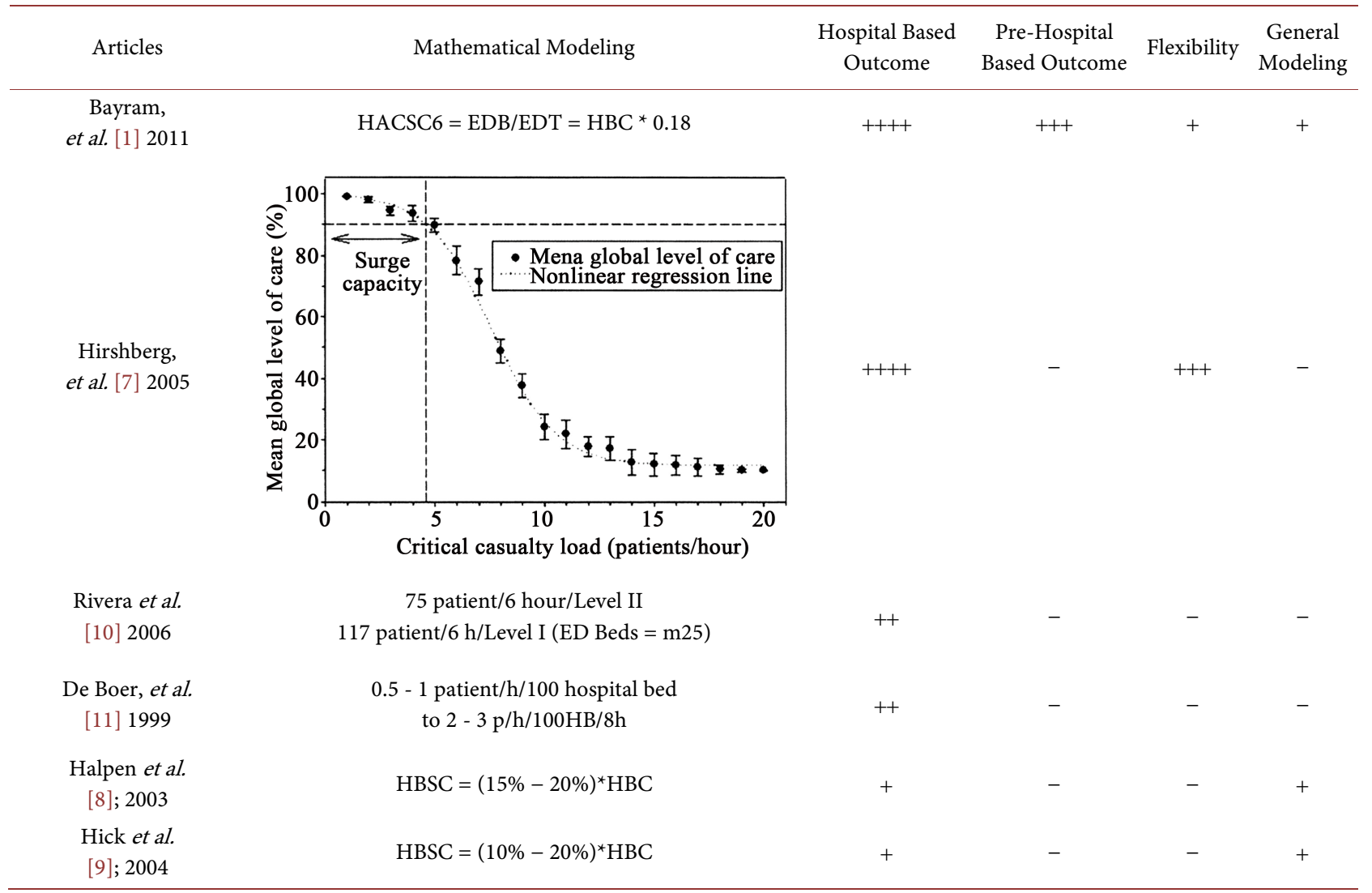

$\mathrm{EDB}=$ emergency department beds; HACSC = hospital acute care surge capacity; HBC = Hospital bed Capacity; HBSC = Hospital Bed Surge Capacity. 
timate surge capacity of this curve of individual hospital based on global level of care of $80 \%$ and $20 \%$ on vertical axis. The point of surge capacity will be defined based on end point of flat portion. The raised idea of our review discussed this point is flexible and hour by hour can be changed. This trend of information should be communicated at least every 2 hours with Incident command center (ICC) in pre hospital setting. On the other hand, predetermined Hospital Acute Care Surge Capacity (HACSC) affects on initial distribution of victims among hospitals. Perhaps, coordination of Hospital setting with Incident Command Center (ICC) by at least 3 sigmoid shape curves can make real the HACSC which was defined by Bayram [1] modeling. Bayram et al. [1] suggested that information need to be revised periodically as well, and it is believed Figure 2 can be near to real modeling if each hospital sends its own curve at least each 2 hour to ICC. The reason that we rely on this new modeling is definition of surge capacity. Koenig [5] defined Hospital surge capacity based on components necessary to level of care for a sudden, unexpected increase in load of patients that exceeds normal capacity. [5] These component are defined in terms of employees, supplies and equipment, resources, and management approaches (staff, supplies, space, and system) [12]. In fact, these components are not predictable. Also, generally there is no unique accepted definition or quantification of its various components, as acknowledged by 2006 Academic Emergency Medicine Consensus Conference entitled "Science of Surge Capacity" [13]. Therefore, modeling will be near to reality if can be changed during the time based on elements.

In other words, merging two accepted previous models can be more practical rather than usage of single method. The reason of this is our comparison in Table 2. Needless to say, practice in field of disaster confirms this idea how we are in need of variables that move by trend of disaster not predefined before that.

\section{Limitation}

One of the limitations of such metrics in surge capacity is all of them are theoretical and cannot generalized to any type of disaster. Because of that we tried to integrate and merged different metrics together. In fact Mass Casualty Incident (MCI) cannot be modeled on a single formula. Our study suggests this question to be raised for future studies that can we use a single metric for predicting surge capacity in Disaster which by own is so unpredictable in all levels? However, curve will stay sigmoid shape in all stage of MCI because of nature of exhaustion.

\section{Conclusion}

This study focused on mathematical analysis of surge capacity, although surge capacity was discussed precisely in consensus conference. It's said that our modeling makes surge capacity more predictable and accountable. This study shows dynamic process of disaster planning based on outcome and reality. This method will add crucial ingredient to the science of surge in disaster and it helps sides, command center and hospitals to collaborate each other. 


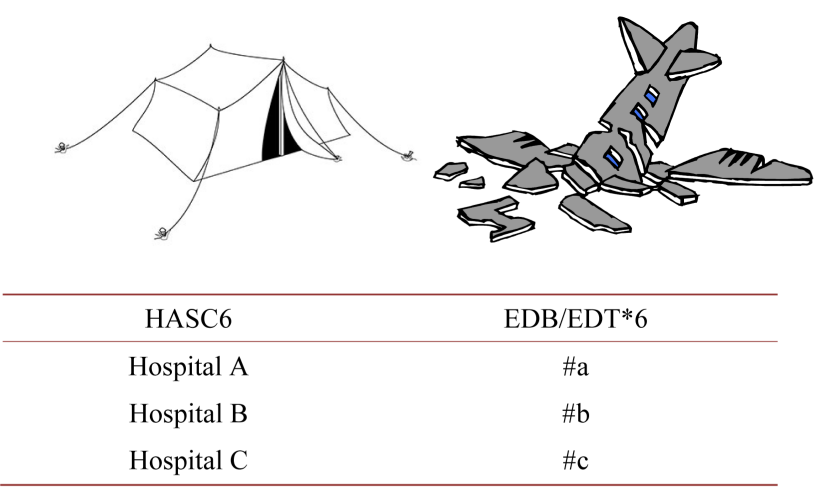

Bayram Modeling [1] in 6 hour.

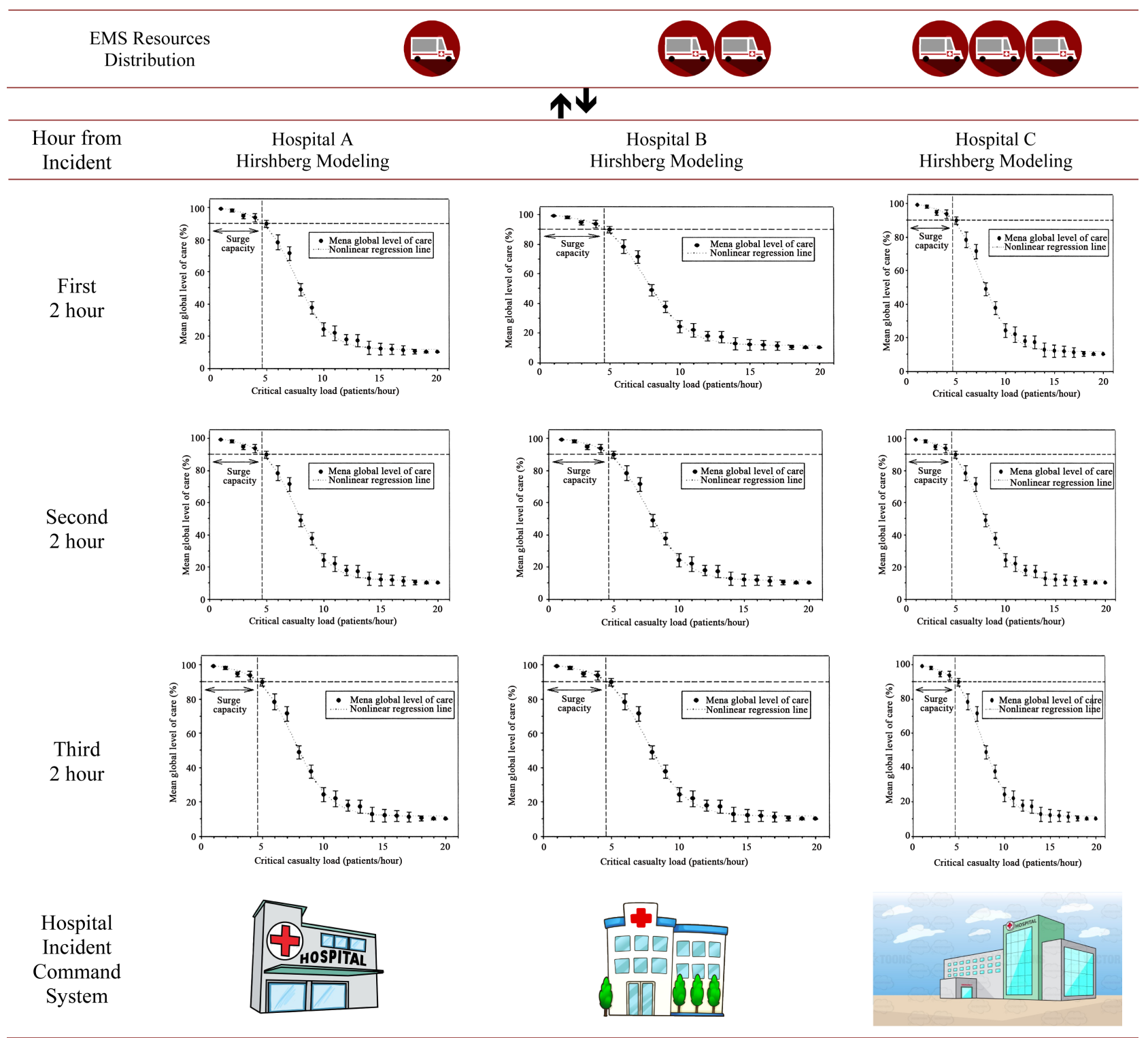

Figure 2. Distribution modeling of resources based on Bayram-Hirshberg (B-H) integrated modeling.

\section{Acknowledgements}

Author thanks Prof. Della Corte, Dr. Ahmad Jalali, and Dr. Ives Hubloue. 


\section{References}

[1] Bayram, J.D., Zuabi, S. and Subbarao, I. (2011) Disaster Metrics: Quantitative Benchmarking of Hospital Surge Capacity in Trauma-Related Multiple Casualty Events. Disaster Medicine Public Health Preparedness, 5, 117-124. https://doi.org/10.1001/dmp.2010.19

[2] American College of Emergency Physicians (2005) Health Care System Surge Capacity Recognition, Preparedness, and Response. Annals of Emergency Medicine, 45, 239. https://doi.org/10.1016/j.annemergmed.2004.10.015

[3] Kaji, A., Koenig, K.L. and Bey, T. (2006) Surge Capacity for Healthcare Systems: A Conceptual Framework. Academic Emergency Medicine, 13, 1157-1159.

[4] Hirshberg, A., Holcomb, J.B. and Mattox, K.L. (2001) Hospital Trauma Care in Multiplecasualty Incidents: A Critical View. Annals of Emergency Medicine, 37, 647-652. https://doi.org/10.1067/mem.2001.115650

[5] Koenig, K.L. and Kelen, G.D. (2006) Executive Summary: The Science of Surge Conference. Academic Emergency Medicine, 13, 1087-1089.

[6] Morton, M.J., De Augustinis, M.L., Velasquez, C.A., Singh, S. and Kelen, G.D. (2015) Developments in Surge Research Priorities: A Systematic Review of the Literature Following the Academic Emergency Medicine Consensus Conference, 2007-2015. Academic Emergency Medicine, 22, 1235-1243.

https://doi.org/10.1111/acem.12815

[7] Hirshberg, A., Scott, B.G., Granchi, T., Wall, M.J., Mattox, K.L. and Stein, M. (2005) How Does Casualty Load Affect Trauma Care in Urban Bombing Incidents? A Quantitative Analysis. The Journal of Trauma, 58, 686-695.

https://doi.org/10.1097/01.ta.0000159243.70507.86

[8] Halpern, P., Tsai, M.C., Arnold, J.L., Stok, E. and Ersoy, G. (2003) Mass-Casualty, Terrorist Bombings: Implications for Emergency Department and Hospital Emergency Response (Part II). Prehospital and Disaster Medicine, 18, 235-241. https://doi.org/10.1017/S1049023X00001102

[9] Hick, J.L., Hanfling, D., Burstein, J.L., et al. (2004) Health Care Facility and Community Strategies for Patient Care Surge Capacity. Annals of Emergency Medicine, 44, 253-261. https://doi.org/10.1016/j.annemergmed.2004.04.011

[10] Rivara, F.P., Nathens, A.B., Jurkovich, G.J. and Maier, R.V. (2006) Do Trauma Centers Have the Capacity to Respond to Disasters? The Journal of Trauma, 61, 949-953. https://doi.org/10.1097/01.ta.0000219936.72483.6a

[11] De Boer, J. (1999) Order in Chaos: Modelling Medical Management in Disasters. European Journal of Emergency Medicine, 6, 141-148. https://doi.org/10.1097/00063110-199906000-00011

[12] Barbisch, D.F. and Koenig, K.L. (2006) Understanding Surge Capacity: Essential Elements. Academic Emergency Medicine, 13, 1098-1102.

[13] Koenig, K.L. and Kelen, G. (2006) Proceedings of the Consensus Conference the Science of Surge, San Francisco, California, May 17 2006, 1087-1088. 
Submit or recommend next manuscript to SCIRP and we will provide best service for you:

Accepting pre-submission inquiries through Email, Facebook, LinkedIn, Twitter, etc. A wide selection of journals (inclusive of 9 subjects, more than 200 journals)

Providing 24-hour high-quality service

User-friendly online submission system

Fair and swift peer-review system

Efficient typesetting and proofreading procedure

Display of the result of downloads and visits, as well as the number of cited articles Maximum dissemination of your research work

Submit your manuscript at: http://papersubmission.scirp.org/

Or contact ojem@scirp.org 